\title{
Mistreatment of the economic impacts of extreme events in the Stern Review Report on the Economics of Climate Change
}

\author{
Roger Pielke Jr.* \\ Center for Science and Technology Policy Research, University of Colorado, 1333 Grandview Ave, Campus Box 488 boulder, Co 80309-0488, USA
}

Received 5 March 2007; received in revised form 21 May 2007; accepted 22 May 2007

\begin{abstract}
The Stern Review on the Economics of Climate Change has focused debate on the costs and benefits of alternative courses of action on climate change. This refocusing has helped to move debate away from science of the climate system and on to issues of policy. However, a careful examination of the Stern Review's treatment of the economics of extreme events in developed countries, such as floods and tropical cyclones, shows that the report is selective in its presentation of relevant impact studies and repeats a common error in impacts studies by confusing sensitivity analyses with projections of future impacts. The Stern Review's treatment of extreme events is misleading because it overestimates the future costs of extreme weather events in developed countries by an order of magnitude. Because the Stern Report extends these findings globally, the overestimate propagates through the report's estimate of future global losses. When extreme events are viewed more comprehensively the resulting perspective can be used to expand the scope of choice available to decision makers seeking to grapple with future disasters in the context of climate change. In particular, a more comprehensive analysis underscores the importance of adaptation in any comprehensive portfolio of responses to climate change.
\end{abstract}

(C) 2007 Elsevier Ltd. All rights reserved.

Keywords: Climate change; Stern Review; Extreme events

\section{Introduction: exploiting an excess of objectivity}

In a provocative article titled "How Science Makes Environmental Controversies Worse" Daniel Sarewitz explains that scientific research results in an "excess of objectivity" in political debates (Sarewitz, 2004). What he means with this phrase is that in most (if not all) cases of political conflict involving science, available research is sufficiently diverse so as to provide a robust resource for political advocates to start with a conclusion and then selectively pick and choose among existing scientific studies to buttress their case. Simply put, to cherry pick, to take the best leave the rest.

An "excess of objectivity," Sarewitz argues, stems not simply from the presence of scientific uncertainty, but also from the fact that,

\footnotetext{
*Tel.: + 13037350451 ; fax: + 13037351576 .

E-mail address: pielke@cires.colorado.edu
}

...nature itself - the reality out there - is sufficiently rich and complex to support a science enterprise of enormous methodological, disciplinary, and institutional diversity. ... science, in doing its job well, presents this richness, through a proliferation of facts assembled via a variety of disciplinary lenses, in ways that can legitimately support, and are causally indistinguishable from, a range of competing, value-based political positions. ... from this perspective, scientific uncertainty, which so often occupies a central place in environmental controversies, can be understood not as a lack of scientific understanding but as the lack of coherence among competing scientific understandings.

Accepting Sarewitz's position complicates the challenge of effectively using science, or other facts, to argue for a particular course of action. The main peril is that an advocate for a particular agenda will first decide upon a course of action and then seek science useful in justifying that course of action. Of course, the advocate's political 
opponent will also settle on a (different) particular agenda and seek out their own justifying science. What then typically happens is that the political debate is transferred to the science used as justifications, rather than taking place explicitly in terms of the values or outcomes at stake that motivated the political controversy in the first place. Scientific debate then becomes a proxy for political debate, and gridlock and inaction often result because science alone cannot resolve political disputes. One way out of this situation is for advisors to clearly associate scientific understandings with a wide range of possible policy options (Pielke, 2007). Rather than narrowing the scope of possible action justified by appeals to selected science, the point of such advice is to expand, or at least comprehensively map, policy options and their relationship to the diversity of current scientific understandings. Such an approach clearly distinguishes the role of advisor from advocate, and advisor from decision maker.

In the area of climate change, there have been countless efforts to provide scientific advice to decision makers. The Stern Review Report on the Economics of Climate Change is one such effort (Stern, 2007). The Stern Review has already achieved several notable successes. Among them, it has focused attention on the challenge of climate change and helped to redirect attention away from debates over science and toward debates over the costs and benefits of alternative courses of action.

However, in making its case for the significant future economic costs of extreme weather events in developed countries the Stern Review commits two significant errors that affect its estimates. In its Chapter 5 the Stern Review concludes, "The costs of climate change for developed countries could reach several percent of GDP as higher temperatures lead to a sharp increase in extreme weather events and large-scale changes." (Stern, 2007, p. 137). This conclusion cannot be supported by the Review's own analysis and references to literature. One error is a serious misrepresentation of the scientific literature, and the second is more subtle, but no less significant. The serious misrepresentation takes the form of inaccurately presenting the conclusions of an unpublished paper on trends in disaster losses. The second error is more complex and involves conflating an analysis of the sensitivity of society to future changes in extreme events, assuming that society does not change, with a projection of how extreme event impacts will increase in the future under the integrated conditions of climatic and societal change. The result of the errors in the Stern Review is a significant overstatement of the future costs of extreme climate events not simply in the developed world, but globally-by an order of magnitude.

In light of these errors if the Stern Review is to be viewed as a means of supporting a particular political agenda, then it undercuts its own credibility and this risks its effectiveness. If instead the Stern Review is to be viewed as a policy analysis of the costs and benefits of alternative courses of actions on climate change, then at least in the case of extreme events it has missed an opportunity to clarify the scope of such actions and their possible consequences, and arguably misdirects attention away from those actions most likely to be effective with respect to future catastrophe losses. In either case, on the issue of extreme events and climate change, the Stern Review must be judged a failure. This short paper documents these errors and suggests how an alternative approach might have been structured.

\section{Stern error \#1: Selected Reference}

The Stern Review suggests that disaster losses are increasing faster than might be explained by changes in wealth, population, and inflation:

The costs of extreme weather events are already high and rising, with annual losses of around $\$ 60$ billion since the 1990 s $(0.2 \%$ of World GDP), and record costs of $\$ 200$ billion in 2005 (more than $0.5 \%$ of World GDP). New analysis based on insurance industry data has shown that weather-related catastrophe losses have increased by $2 \%$ each year since the 1970 s over and above changes in wealth, inflation and population growth/movement. ${ }^{1}$

The source for the "new analysis" statement is a background paper prepared by Muir-Wood and colleagues as input to a workshop that Peter Höppe and I organized in May, 2006 in Hohenkammer, Germany on disasters and climate change (Muir-Wood et al., 2006; Höppe and Pielke, 2006). In their background paper Muir-Wood et al. do indeed report a 2\% annual increase in losses since 1970 after adjusting for various societal factors. What the Stern Review does not report of Muir-Wood et al. is that they find no trend in losses over the longer period 1950-2005 and that Muir-Wood et al. acknowledge that the trend that they find is "dominated" by the 2004 and 2005 hurricane seasons in the US. In other words, the trend is not global but the result of hurricane losses in the US. Muir-Wood et al. are consequently very cautious and responsible in how they report their analysis, avoiding any strong claims of attribution of the trend. Presumably this is one reason why at the Hohenkammer workshop Muir-Wood signed on to the workshop consensus statements, which included the following:

Because of issues related to data quality, the stochastic nature of extreme event impacts, length of time series, and various societal factors present in the disaster loss record, it is still not possible to determine the portion of

\footnotetext{
${ }^{1}$ Stern (2007) is published by Cambridge University Press. The version referred to in this paper is found online at: http://www.hm-treasury.gov.uk/ independent_reviews/stern_review_economics_climate_change/stern_review_ report.cfm The specific focus is on Chapter 5, "Costs of climate change in developed countries" available at: http://www.hm-treasury.gov.uk/media/ 9A2/A6/Chapter_5__Developed_Country_Impacts.pdf
} 
the increase in damages that might be attributed to climate change due to GHG emissions... In the near future the quantitative link (attribution) of trends in storm and flood losses to climate changes related to GHG emissions is unlikely to be answered unequivocally.
Box 1 reproduces the workshop consensus statements in full, which acknowledge the reality of climate change but also the challenges of attribution of loss trends to greenhouse gas emissions. There is no peer-reviewed literature, much less a scientific consensus, at present suggesting that it is possible to ascribe an annual increase in economic

Box 1

Consensus (unanimous) statements of the Hohenkammer workshop on climate change and disaster losses (Höppe and Pielke, 2006)

1. Climate change is real, and has a significant human component related to greenhouse gases.

2. Direct economic losses of global disasters have increased in recent decades with particularly large increases since the 1980s.

3. The increases in disaster losses primarily result from weather related events, in particular storms and floods.

4. Climate change and variability are factors which influence trends in disasters.

5. Although there are peer-reviewed papers indicating trends in storms and floods there is still scientific debate over the attribution to anthropogenic climate change or natural climate variability. There is also concern over geophysical data quality.

6. IPCC (2001), did not achieve detection and attribution of trends in extreme events at the global level.

7. High quality long-term disaster loss records exist, some of which are suitable for research purposes, such as to identify the effects of climate and/or climate change on the loss records.

8. Analyses of long-term records of disaster losses indicate that societal change and economic development are the principal factors responsible for the documented increasing losses to date.

9. The vulnerability of communities to natural disasters is determined by their economic development and other social characteristics.

10. There is evidence that changing patterns of extreme events are drivers for recent increases in global losses.

11. Because of issues related to data quality, the stochastic nature of extreme event impacts, length of time series, and various societal factors present in the disaster loss record, it is still not possible to determine the portion of the increase in damages that might be attributed to climate change due to GHG emissions

12. For future decades the IPCC (2001) expects increases in the occurrence and/or intensity of some extreme events as a result of anthropogenic climate change. Such increases will further increase losses in the absence of disaster reduction measures.

13. In the near future the quantitative link (attribution) of trends in storm and flood losses to climate changes related to GHG emissions is unlikely to be answered unequivocally.

Policy implications identified by the workshop participants

1. Adaptation to extreme weather events should play a central role in reducing societal vulnerabilities to climate and climate change.

2. Mitigation of GHG emissions should also play a central role in response to anthropogenic climate change, though it does not have an effect for several decades on the hazard risk.

3. We recommend further research on different combinations of adaptation and mitigation policies.

4. We recommend the creation of an open-source disaster database according to agreed upon standards.

5. In addition to fundamental research on climate, research priorities should consider needs of decision makers in areas related to both adaptation and mitigation.

6. For improved understanding of loss trends, there is a need to continue to collect and improve longterm and homogenous data sets related to both climate parameters and disaster losses.

7. The community needs to agree upon peer-reviewed procedures for normalizing economic loss data. 
losses related to extreme weather events of $2 \%$ (or any other number) per year to greenhouse gas emissions. The Stern Review chose to ignore the consensus view in favor of selectively citing a single study.

Furthermore, the Stern Review uses the Muir-Wood et al. (2006) as the sole basis for projecting future global losses from extreme events (see Table 5.2, p. 138). This means that the Stern Review's conclusions on the costs of future extreme events under conditions of climate change are based almost entirely on projections of future hurricane losses, which Stern projects somewhat mysteriously will increase to $1.3 \%$ of global GDP or higher. Its reliance on estimate of tropical cyclones losses is both direct and indirect. Its summary Table 5.2 on p. 138 indicates that increasing losses from hurricanes are one or two orders of magnitude larger than other losses that it has examined. It also relies indirectly on estimates of hurricane losses as its summary Table 5.2 shows that its global estimates are based on using the $2 \%$ annual increase figure from MuirWood et al. (2006) which, as discussed above, is based entirely on trends in US hurricane losses. Therefore, it is appropriate to conclude that the Stern Review's estimates of future losses in developed countries, and indeed globally, are based on projections of future losses related to hurricane.

To summarize, to justify its conclusion of large increases in future economic losses of extreme events due to climate change, the Stern Review misrepresents a single non-peerreviewed, heavily caveated background paper to a workshop which itself resulted in conclusions counter to those presented by Stern. The Stern Review neglected to focus either on a consensus view among relevant experts (including the lead author of the study that it did cite) which asserts that it is presently not possible to quantify the role of greenhouse gas emissions in trends in disaster losses. Thus, the Stern Review provides no scientific basis for its projections for future increases in losses in developed countries (and the world) related to extreme events under conditions of future climate change.

\section{Error \#2: exploiting the unreality of a static society}

In its portrayal of the effects of extreme events in a changing climate on society, the Stern Review repeats and reinforces a common methodological error by assuming that climate will change but society will remain the same (cf. Pielke and Sarewitz, 2005; Adger et al., 2003; Lorenzoni et al., 2000). Such a methodology - a sensitivity analysis - can serve as a useful simplification because it can illustrate the independent effects that climate change will have on society, i.e., all else being equal. But of course all else is not equal. Not only does climate change, so too does society, sometimes in ways that are far more significant for future impacts than any projected changes in climate. When a sensitivity analysis is mistakenly treated as a prediction or projection, it can mislead.
The Stern Review reports that changes in future storm intensity would result in increasing damages:

Two recent studies have found that just a $5-10 \%$ rise in the intensity of major storms with a $3{ }^{\circ} \mathrm{C}$ increase in global temperatures could approximately double the damage costs, resulting in total losses of $0.13 \%$ of GDP in the USA each year on average or insured losses of $\$ 100-150$ billion in an extreme year (2004 prices). [emphasis added]

The footnote used to support this assertion points to the "two recent studies":

Recent papers from Nordhaus (2006) and the Association of British Insurers (2005a) examined consequences of increased hurricane wind-speeds of $6 \%$ on loss damages, keeping socio-economic conditions and prices constant. [emphasis added] ${ }^{2}$

The emphasized text in the excerpt makes clear that the cited studies perform sensitivity analyses and do not provide a prediction or a projection, because the societal variables are held constant. Yet the Stern Review's analysis conflates the results of the sensitivity analyses with a projection of future losses, leading to a dramatic overstatement of the future costs of catastrophes. Understanding this overstatement requires a detailed understanding of the studies cited in the Stern Review.

In 2005, the Association of British Insurers (ABI) released a report on damages from extreme weather events and climate change (ABI, 2005a, b). A close look at the $\mathrm{ABI}$ reports indicates that future societal changes, and not climate changes, are the primary drivers of increasing disaster losses. The ABI overview report uses a catastrophe model, such as used by the insurance and reinsurance industries to estimate the risk of losses, to project future increases in damage costs related to climate change and extreme events. ${ }^{3}$ The ABI report observes:

This study is one of the first to use insurance catastrophe models to examine the potential impacts of climate change on extreme storms. It focuses on one of the most costly aspects of today's weather-hurricanes, typhoons, and windstorms, because of their potential to cause substantial damage to property and infrastructure.

The report (2005a, p. 6) concludes of tropical cyclones in the US and Japan, and European windstorms:

Under [the report's] climate change scenarios, total average annual damages from these three major storm

\footnotetext{
${ }^{2}$ The two references used by the Stern Report in this passage to justify its estimates of the future impacts of climate change are (ABI 2005a, b) and Nordhaus (2006). This section discusses both.

${ }^{3}$ In the ABI reports the model is provided by a firm called Applied Insurance Research, Inc. headquartered in Boston, MA.
} 
Table 1

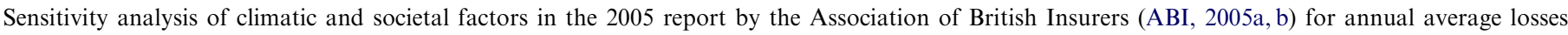
related to tropical cyclones for 2085

(a) United States

Storm intensity increase

US baseline $\$ 9.5$ billion

Increase in damage, due only to climate change ( $\$$ billion)

Percentage increase over baseline due to climate change

Increase in damage due to societal change only ( $\$$ billion, percent increase)

Ratio of effects of societal change to climate change (columns 3-5)

(b) Japan

Japan Baseline $\$ 4.0$ billion

Increase in damage, due only to climate change ( $\$$ billion)

Percentage increase over baseline due to climate change

Adjusted for $50 \%$ decrease in population

Increase in damage due to per capita wealth change only ( $\$$ billion, percent increase)

Ratio of effects of societal change to climate change (columns 3-5)

$4 \%$

$4 \%$

4.5

$47 \%$

$51.8,545 \%$

11.5-1

$4 \%$

2.0

$50 \%$

$10.4,259 \%$
$25 \%, 1.0$

10.4-1

$\begin{array}{ll}6 \% & 9 \% \\ 7.1 & 11.0 \\ 75 \% & 116 \% \\ 7.3-1 & 4.7-1\end{array}$

$6 \%$

2.5

$63 \%$

$31.5 \%, 1.25$

$8.3-1$

The increase in damages due to climate change reported in ABI $(2005 \mathrm{a}, \mathrm{b})$ are slightly different. The numbers presented here are taken from $2005 \mathrm{a}$, and the differences are small enough not to matter for this analysis.

types could increase by up to $\$ 10.5$ [billion] above a baseline of $\$ 16.5$ [billion] today, representing a $65 \%$ increase. $^{4}$

The report notes explicitly that it is conducting a sensitivity analysis because it does not include all relevant variables necessary to produce a projection or prediction:

These loss estimates do not include likely increases in society's exposure to extreme storms, due to growing, wealthier populations, and increasing assets at risk. For example, if Hurricane Andrew had hit Florida in 2002 rather than 1992, the losses would have been double, due to increased coastal development and rising asset values. ${ }^{5}$

What is the practical significance of the distinction between a sensitivity analysis and a projection? Consider the case of Japan, which the ABI report estimates will see its population reduced by half by 2100 . Not factoring in this decrease in exposure would lead to an overestimate of the future losses by a factor of two. In other words, if today's population of Japan was half its present value, its current baseline of average tropical cyclone damages would be proportionately lower, and so too would be the future impacts of extreme events even assuming changes in climate. In the face of such significant projected societal changes it would be misleading to project future damages by holding societal variables constant and simply changing the climate variables. The ABI reports acknowledge the

\footnotetext{
${ }^{4}$ The $\$ 16.5$ billion baseline is comprised on increasing losses from tropical cyclones affecting the US and Japan, and also extra-tropical cyclones affecting Europe. The baseline losses for the US and Japan are $\$ 13.5$ billion. The analysis here considers only the tropical cyclones affecting the US and Japan, which account for \$9.6 billion of the $\$ 10.5$ billion climate change-related increase reported by ABI. The $\$ 10.5$ billion value is the mid-range figure provided by $\mathrm{ABI}$.

${ }^{5}$ The fact that losses due to societal factors alone are doubling every 10 years, whereas those related to climate change are doubling over 70 says something about their relative importance (see Pielke, in press). The Stern Review missed this obvious comparison.
}

importance of societal change, but do not report quantitatively their independent effects on future losses.

It is, however, possible to determine the independent impact of societal changes on future losses from the data and assumptions in the ABI reports. Such an analysis indicates the overwhelming importance of the changing societal conditions in comparison to the changing climate conditions. Consider that if damages increase proportionately to the increase in population and per capita wealth (in constant dollars, cf. Pielke, in press), then under the ABI assumptions in the US societal changes alone would increase damages by $\$ 51.8$ billion, as compared to a maximum increase of $\$ 11.0$ billion due to climate changes, and in Japan, after adjusting for decreasing population and increasing wealth, $\$ 10.4$ billion of the increase is due to growing wealth and a maximum $\$ 2.25$ billion increase due to climate changes. ${ }^{6}$ Table $1 \mathrm{a}$ and $\mathrm{b}$ compares the relative importance of changes in climate (top rows) and changing per capita wealth and populations on future damages (bottom rows) based on the low, mid, and high assumptions for changes in storm intensities used in the ABI report for the year 2085. Table 1a shows that for the US for every $\$ 1.00$ in future losses related to tropical cyclones due to changes in climate we should expect between $\$ 4.70$ and $\$ 11.50$ in additional losses due to changes in population and wealth. Similarly, Table $1 \mathrm{~b}$ shows for Japan that societal factors account for between $\$ 4.60$ and $\$ 10.40$ in increased losses for every dollar in increasing losses due to changes in storm intensity, again, under the assumptions of the ABI.

The Stern Review's methodological error is based on treatment of a sensitivity analysis focused only on the effects of climate change in the context of total GDP as a projection. Thus, rather than telling the reader what losses

\footnotetext{
${ }^{6}$ The values of $\$ 11.0$ billion and $\$ 2.25$ billion for the US and Japan, respectively, refer to ABIs high-end estimates.
} 
might be expected in the future, the Stern Review's results instead indicate the effect that future climate change would have on today's world GDP. This is misleading because both GDP and societal vulnerability are increasing at a rate that will increase catastrophe losses much faster than the independent effects of climate change. Stern's argument begins by claiming that present-day catastrophe losses are $0.2 \%$ of global GDP today and ends by projecting a value an order of magnitude higher, several percent of global GDP, which is of the same magnitude of the Review's overall projections of the total costs of climate change of $5-20 \%$ of global GDP.

It describes its methodology as follows:

Based on simple extrapolation through to the 2050s. The lower bound assumes a constant $2 \%$ increase in costs of extreme weather over and above changes in wealth and inflation. The upper band assumes that the rate of increase will increase by $1 \%$ each decade, starting at $2 \%$ today, $3 \%$ in $2015,4 \%$ in $2025,5 \%$ in 2035 , and $6 \%$ in 2045. These values are likely underestimates: (1) they exclude "small-scale" events which have large aggregate costs, (2) they exclude data for some regions (Africa and South America), (3) they fail to capture many of the indirect economic costs, such as the impacts on oil prices arising from damages to energy infrastructure, and (4) they do not adjust for the reductions in losses that would have otherwise occurred without disaster mitigation efforts that have reduced vulnerability.

There is no empirical basis in the literature either cited by the Stern review or elsewhere for asserting such acceleration in losses, and there is no empirical evidence for such a trend in the existing loss record (Höppe and Pielke, 2006). For example, in the case of the US if the Stern Review instead also properly considered the effects of societal change as presented in ABI (2005b) then the Review would have concluded that societal changes alone would increase the baseline losses from $\$ 9.5$ billion to $\$ 61.3$ billion. Using the ABI methodology the effects of human-caused climate change on this baseline would be $\$ 51.0$ billion. $^{7}$ The total projected annual losses in 2085 would therefore be $\$ 112.3$ billion. $^{8}$ Assuming that US GDP increases by $1.5 \%$ per year results in a GDP of $\$ 42.1$ trillion in 2085. Tropical cyclone losses in the US for 2085 implied by the ABI report are therefore $0.27 \%$ of GDP $(=0.1123 / 42.1)$. If US GDP instead increases annually by $2.5 \%$ then tropical cyclone losses in the US for 2085 would instead be $0.12 \% .{ }^{9}$ For comparison Nordhaus (2006) (also cited by Stern) suggests that US losses under

\footnotetext{
${ }^{7}$ Calculated as the ratio of the effects of climate change on the current baseline $(83 \%=7.9 / 9.5)$ times the future baseline $=83 \% * 61.3=51.0$. ABI (2005a) suggests that this value is $75 \%$.

${ }^{8}$ Using the ABI high end estimate results in a projection of $\$ 132.3$ billion.

${ }^{9}$ For the high end projection losses as a percentage 0f 2085 GDP are 0.14 and 0.31 for $1.5 \%$ and $2.5 \%$ annual growth in US. GDP, respectively.
}

a doubling of carbon dioxide concentrations would increase to $0.13 \%$ of GDP.

Yet inexplicably, the Stern Review concludes that US tropical cyclone losses will increase from $0.6 \%$ of GDP today to $1.3 \%$ of GDP under $2^{\circ}$ of warming (Table 5.2). Yet, on page 130 the Stern Review cites Nordhaus (2007) to suggest that $2-3^{\circ}$ of warming could double tropical cyclone losses from $0.06 \%$ of GDP (2005 losses) to $0.13 \%$ (future losses). There is no justification provided for increasing the Nordhaus (2007) values by a factor of 10 . This apparent error (simply a typo?) is consistent with the Stern Review's overstatement of future economic losses from extreme weather events more generally.

If one accepts that global losses as a percentage of GDP would indeed to double due to a climate change of $3^{\circ}$, then according to the estimates in the Stern Review they would increase from $0.2 \%$ of global GDP to $0.4 \%$. However, the faster that GDP increases, particularly in developing countries, then the smaller catastrophe losses related to climate change will be in comparison. It is therefore unlikely that even a doubling can be supported once the focus turns from the US to the rest of the world. There is simply no basis to conclude, as the Stern Review has, that losses will increase to several percent of global GDP or higher. Consequently the Stern Review's estimates of increasing losses from extreme weather events, which it asserts total up to several percent of global GDP, are not supported by the references that it cites or the analysis that it provides.

More generally, Stern's mistreatment of future economic losses is not unique. It is directly related to analyses such as the ABI reports that neglect the consequences of societal change. For instance, in Science, Mills (2005) makes the following claim about the ABI report:

As an indication of the potential value of emissions reductions, the Association of British Insurers, in collaboration with US catastrophe modelers, estimated that US hurricane or Japanese typhoon losses would vary by a factor of five for scenarios of $40 \%$ and $116 \%$ increase in pre-industrial atmospheric $\mathrm{CO}_{2}$ concentrations.

As indicated about, Mills' claim about total losses is decidedly not what the ABI report estimated. When assumptions and qualifications are dropped, and sensitivity analyses are turned into projections, meanings can change dramatically, sometimes $180^{\circ}$. When reports such as those by the ABI are subsequently misrepresented in the peer reviewed literature it becomes exceedingly difficult to identify and correct the error as the results in the peerreviewed paper are then cited. For example, in his chapter on extreme event losses Stern references the work of Mills (which relies in error on the ABI reports) no fewer than 10 times and does not reference work that has challenged and sought to correct the misrepresentations (e.g., Pielke, 2005). 
Contrary to the Stern Review's reliance on the ABI (2005a, b) reports on climate change and Nordhaus (2006) to support dramatic projections of disaster losses increasing by an order of magnitude, a close look indicates that the reports actually support a far different conclusion. Climate change is a less significant a factor than societal change for projecting future catastrophe losses.

\section{How the Stern Review might have addressed the economics of extreme events: robust science for robust decision making}

The Stern Review might have presented a more comprehensive analysis of the inter-relationship of future climate change and societal change. Pielke (in press) provides one example of how an integrated sensitivity analysis might be done in the case of the global economic impacts of tropical cyclones (e.g., hurricanes) to 2050 under conditions of climate change and societal change, and this approach is briefly summarized here.

The impacts of climate on society result from the interaction of a climate event and societal vulnerability to experiencing impacts. The goal of the sensitivity analysis methodology used in Pielke (in press) is to examine various combinations of climate change and societal conditions (and the relationship of the two) to assess future economic impacts of tropical cyclones and the relative potential for different approaches to their mitigation. The goal is not to perform a cost-benefit analysis of policy options. Nor is the goal to predict future impacts or to arbitrarily select among different scientific understandings. Rather the goal is to explore the potential effectiveness of alternative approaches to addressing future tropical cyclone losses in the context of a wide range of assumptions about the future.

In order to assess possible future damage to tropical cyclones relative to today requires a number of assumptions. Pielke (in press) uses assumptions about societal changes (i.e., changes in per capita wealth and population), climate change (i.e., different scenarios for changes in storm intensity), and the relationship of climate change to damage (i.e., different relationships between the two). This analysis allows for a comparison of the potential effectiveness of mitigation policies and adaptation policies.

For example, consider a hypothetical emissions reduction policy that leads to a $10 \%$ reduction in the projected increase atmospheric greenhouse gas concentrations in 2050. Assuming that greenhouse gas reductions have an instantaneous (i.e., contemporaneous with the reductions) and proportional (i.e., a $50 \%$ decrease in emissions decreases the projected increase in tropical cyclone intensity by $50 \%$ ) effect on tropical cyclone intensity, ${ }^{10}$ then a policies that lead to a $10 \%$ decrease in atmospheric

\footnotetext{
${ }^{10}$ Of course, the real climate system does not work this way, and the effects of mitigation on hurricane behavior remains poorly understood, but it is certainly less direct than the oversimplification offered here.
}

carbon dioxide concentrations in 2050 would (under the assumptions here) decrease the projected increase in hurricane intensities by $10 \%$ in 2050 .

Under these various assumptions the largest maximum potential effectiveness of a $10 \%$ reduction in the projected increase in greenhouse gas concentrations by 2050 for reducing future global tropical cyclone damage is far less than the maximum potential effectiveness of adaptation (i.e., reducing the vulnerability of people and property) by a ratio of about $8-22$ to 1 , depending on socio-economic scenario. ${ }^{11}$

Because a $10 \%$ reduction is quite small compared to some reductions currently being discussed, one can also examine the potential effectiveness of instantaneous climate stabilization at 2006 values. Under no scenario examined in Pielke (in press) does this unrealistically aggressive degree of mitigation result in a greater potential effectiveness than vulnerability reduction for reducing future losses from tropical cyclones around the world (with a ratio of about $1.3-3$ to 1). It is therefore appropriate to conclude that vulnerability reduction is potentially more effective under any theoretically possible mitigation scenario.

Greenhouse gas mitigation may certainly be justified for other reasons, such as its cost-effectiveness, but if the case of tropical cyclones is representative of other disasterrelated phenomena, then even if greenhouse gas mitigation polices were cost-free, then vulnerability reduction would still have far greater potential to address the mounting toll of disaster losses because emissions reduction policies can only address a subset of the multiple causes of increasing losses. It should be underscored that this exercise was conducted using conservative projected societal changes (i.e., wealth, population) as well as unrealistic assumptions about climate behavior. Using larger societal changes and more realistic assumptions about climate science would result in a larger potential effectiveness ratio in favor of vulnerability reduction. Thus, the effectiveness of mitigation is certainly overstated in this analysis. These results are robust even under the full range of assumptions about changes in tropical cyclone intensities. The longer the time scale, the greater the role of the societal factors assuming continued growth in wealth and/or population.

To emphasize, the analysis summarized here should not be interpreted as an argument against mitigation of greenhouse gases. And there is no suggestion here that human-caused climate change is not real or should not be of concern. Instead, this simple analysis under the most favorable assumptions for mitigation indicates that in the coming decades any realistically achievable mitigation policies can have at best only a very small and perhaps imperceptible effect on global tropical cyclone damage,

\footnotetext{
${ }^{11}$ Pielke (in press) uses an informal expert elicitation to arrive at a projected $18 \%$ increase in tropical cyclone intensity by 2050 . Using a $36 \%$ increase reduces the ratio to $5-13$ to 1 depending on socio-economic scenario.
} 
whatever the costs of those policies might happen to be. This reality explains why adaptation necessarily must be at the center of climate policy discussions and must be viewed as a complement to mitigation policies, rather than being viewed simply as the costs of failed mitigation, as suggested by the Stern Review. It also helps to explain why mitigation policies in the short-term necessarily must be focused on their non-climate benefits. These are decidedly different conclusions than were presented in the Stern Report.

Most importantly these results show how misleading it is to use tropical cyclone damage - and disaster losses more generally - as a primary justification for greenhouse gas mitigation when other actions have far more potential effectiveness. The images of storm-spawned death and destruction are no doubt compelling, but it is misleading or disingenuous to suggest that energy policies can have an appreciable effect on damages in coming decades. The only way to arrive at effects on damages from human-caused climate change that exceed the effects of societal change is to hold society constant and focus only on the climate component, which is what was done in the $\mathrm{ABI}$ reports and subsequently done (perhaps unknowingly) in how the Stern Review used the ABI reports. Climate change deserves serious attention and policy action on mitigation makes sense, but when compared with available alternatives for addressing the escalating costs of disasters adaptive policies deserve to be in the fore.

\section{Conclusion: science advisors: issue advocate or honest broker?}

This brief critique of a small part of the Stern Review finds that the report has dramatically misrepresented literature and understandings on the relationship of projected climate changes and future losses from extreme events in developed countries, and indeed globally. In one case this appears to be the result of the misrepresentation of a single study. This cherry picking damages the credibility of the Stern Review because it not only ignores other relevant literature with different conclusions, but it misrepresents the very study that it has used to buttress its conclusions. In a second case, Stern repeats and reinforces a common methodological mistake by presenting a sensitivity analysis as if it were a projection or prediction. When one takes a closer look at the sensitivity analysis one finds that it in fact shows that future societal changes, and not climate changes, are the primary drivers of disaster losses and will be for the foreseeable future. The net result of these errors is that the Stern Review overestimates future losses from extreme events by one order of magnitude.

How one ultimately evaluates the Stern Review's treatment of disaster losses and climate change will depend upon how one views the purpose of the Stern Review as a source of advice to government (cf. Pielke, 2007). On the one hand, if it is intended as a tool of advocacy - that is, as a means of reducing the scope of available choice to some predetermined option - then the Stern Review might be evaluated as effective. It has carefully presented a perspective that emphasizes the role of climate change in enhancing the costs of future disasters. It has reached this conclusion by selectively reporting and misrepresenting the scientific literature. This selective reporting would little differentiate the Stern Review from many advocacy documents that one finds from non-governmental organizations and companies seeking to reduce the scope of choice to some desired outcome. As indicated in this short paper, explaining the misrepresentations in the Stern Review requires some effort, which makes the misrepresentation difficult to explain, much less correct.

On the other hand, if the Stern Review is intended to clearly identify the scope of available options available to decision makers, or even expand those options, it must be judged a failure in its consideration of extreme events and climate change. The Stern Review has clouded rather than clarified the issue of economic losses related to extreme events in the context of climate change. The reality is that societal changes are by far the overwhelming most important driver of projected future losses, under the assumptions and conclusions of the very studies that Stern cites to emphasize the singular importance of climate change. From a policy perspective, what these results mean is that sustainable development must play a large role in any climate policy that is focused on addressing the future impacts of extreme events. Stern misleads by deemphasizing adaptation as sustainable development in favor of a narrow focus on energy policy (cf. Pielke et al., 2007). To the extent that decision makers view the Stern Review not as advocacy document, but as an honest broker of policy options, the Review is likely to mislead and distract attention from those action that have the most potential to address the ever growing toll of extreme events.

\section{References}

Adger, W.N., Huq, S., Brown, K., Conway, D., Hulme, M., 2003. Adaptation to climate change in the developing world. Progress in Development Studies 3, 179-195.

Association of British Insurers (ABI), 2005a. Financial Risks Of Climate Change: Summary report. Association of British Insurers, London. Available from: 〈http://www.abi.org.uk/Display/File/Child/ 552/Financial_Risks_of_Climate_Change.pdf $\rangle$.

Association of British Insurers (ABI), 2005b. Financial Risks Of Climate Change: Technical Annexes. Association of British Insurers, London. Available from:〈http://www.abi.org.uk/Display/File/Child/ 552/Technical_Annexes_climatetechnical.pdf $\rangle$.

Höppe, P., Pielke, Jr., R.A., (eds.), 2006. Workshop on climate change and disaster losses: understanding and attributing trends and projections. Final Workshop Report, 25-26 May, Hohenkammer, Germany. $\langle$ http://sciencepolicy.colorado.edu/sparc/research/projects/extreme_ events/munich_workshop/workshop_report.html $\rangle$.

Lorenzoni, I., Jordan, A., Hulme, M., Turner, R.K., O'Riordan, T., 2000. A co-evolutionary approach to climate change impact assessment: Part I. Integrating socio-economic and climate change scenarios. Global Environmental Change-Human and Policy Dimensions 10, 57-68.

Muir-Wood, R., Miller, S., Boissonade, A., 2006. The search for trends in a global catalogue of normalized weather-related catastrophe losses. Workshop on climate change and disaster losses: Understanding and attributing trends and projections. Final Workshop Report, 25-26 
May, Hohenkammer, Germany, 〈http://sciencepolicy.colorado.edu/ sparc/research/projects/extreme_events/munich_workshop/workshop_ report.html $>$.

Nordhaus, W.D., 2006. The economics of hurricanes in the US. Prepared for the Snowmass Workshop on Abrupt and Catastrophic Climate Change, Snowmass, CO: Annual Meetings of the American Economic Association. Available from: 〈http://nordhaus.econ.yale.edu/hurricanes. pdf $>$.

Pielke Jr., R.A., 2005. Attribution of disaster losses. Science 310, 1615.

Pielke Jr., R.A., 2007. The Honest Broker Making Sense of Science in Policy and Politics. Cambridge University Press, Cambridge, UK.
Pielke Jr., R.A., in press. Future economic damage from tropical cyclones: Sensitivities to societal and climate changes. Philosophical Transactions of the Royal Society.

Pielke Jr., R.A., Sarewitz, D., 2005. Bringing society back into the climate debate. Population and Environment 26, 255-268.

Pielke, R.A., Prins, G., Rayner, S., Sarewitz, D., 2007. Lifting the taboo on adaptation. Nature 445, 597-598.

Sarewitz, D., 2004. How Science makes environmental controversies worse. Environmental Science \& Policy 7, 385-403.

Stern, N., 2007. The Economics of Climate Change: The Stern Review. Cambridge University Press, Cambridge, UK. 